\title{
The Role of Routine Preoperative Magnetic Resonance Imaging in Idiopathic Scoliosis: A Ten Years Review
}

\author{
Ebrahim Ameri ${ }^{1}$, Ali Andalib ${ }^{2}$, Hossein Vahid Tari ${ }^{3}$, Hasan Ghandhari ${ }^{1}$ \\ ${ }^{1}$ Department of Orthopaedics, Shafa Yahiaeian Hospital, Iran University of Medical Sciences, Tehran, Iran \\ ${ }^{2}$ Department of Orthopaedics, Alzahra Hospital, Isfahan University of Medical Sciences, Isfahan, Iran \\ ${ }^{3}$ Department of Orthopaedics, Rasool Akram Hospital, Iran University of Medical Sciences, Tehran, Iran
}

\begin{abstract}
Study Design: Prospective study.
Purpose: To determine the role of routine preoperative magnetic resonance imaging (MRI) to detect the incidence and risk factors for intraspinal anomalies in patients with idiopathic scoliosis.

Overview of Literature: The incidence and risk factors for intraspinal anomalies in patients with idiopathic scoliosis are controversial, and the indications for preoperative MRI in these patients vary among centers.

Methods: Information on patients with idiopathic scoliosis who were surgical candidates over 10 years (age at presentation, sex, magnitude and apex of major curve, intraspinal anomalies detected by MRI, and neurological examination results) were recorded, the patients were grouped according to the intraspinal anomaly, and the data were analyzed.

Results: Of the 271 patients with idiopathic scoliosis, 27 had neuroaxial abnormalities (9.9\%). Of these 27 patients, 14 (52\%) underwent a neurosurgical procedure. Significant differences were observed in the frequency of early disease onset and male sex $(p<0.05)$ between the group of patients with neuroaxial abnormalities on preoperative MRI and those who did not have a cord anomaly. No difference was detected in the magnitude or direction of the curve.

Conclusions: Neuroaxial abnormalities in patients with idiopathic scoliosis and a normal neurological examination were highly frequent (9.9\%). Missing these abnormalities before surgery could inflict catastrophic postoperative complications. The incidence of neuroaxial abnormalities was higher in male patients and in those with early onset disease. Thus, MRI is essential for all patients with idiopathic scoliosis who require medical intervention.
\end{abstract}

Keywords: Spinal cord; Scoliosis; Magnetic resonance imaging; Deformity

\section{Introduction}

Scoliosis is a lateral deviation in the spine from the midline. It is usually accompanied by vertebral rotation, leading to three-dimensional deformities on sagittal, coronal, and frontal views. The most common form is idiopathic scoliosis, in which the cause of the deformity is unknown. Other types include congenital scoliosis, caused by a vertebral defect or segmentation, and neuromuscular scoliosis, caused by a neuromuscular disorder, such as cerebral

Received Dec 31, 2014; Accepted Jan 29, 2015

Corresponding author: Hasan Ghandhari

Department of Orthopaedics, Shafa Yahiaeian Hospital, Iran University of Medical Sciences,

Mojahedin Eslam Avenue, Tehran, Iran

Tel: +98-912-149-3926, Fax: +98-912-149-3926, E-mail: Drghandhari.h@gmail.com 
palsy or poliomyelitis [1]. Idiopathic scoliosis is confirmed in patients with scoliosis if there are no comorbid diseases on a physical examination and no spinal anomalies on a simple vertebral radiograph [2].

Although the etiology of idiopathic scoliosis is unknown, a relationship has been observed between scoliosis and neuroaxial abnormalities, such as syringomyelia or a Chiari malformation. More neuroaxial abnormalities have been identified in patients with idiopathic scoliosis since the development of magnetic resonance imaging (MRI) [3-6].

A higher probability of neuroaxial abnormalities has been reported in patients with idiopathic scoliosis $<11$ years of age (26.7\%). Other cases requiring MRI based on a presurgical examination include patients with pain, rapid progression, a left thoracic deformity, neurological disorders (changes in abdominal reflexes), and other neurological findings, such as bladder and bowel dysfunctions [1].

Not all diagnosed abnormalities require intervention, but it is essential to identify these abnormalities before surgery to correct scoliosis and outfitting with instrumentation because correcting scoliosis in a patient with a missed diagnosis results in catastrophic complications [7]. MRI is the most sensitive modality for identifying neuroaxial abnormalities. Yet, the indications for MRI in patients with idiopathic scoliosis vary among centers.

The prevalence of intraspinal anomalies in patients with idiopathic scoliosis varies and is unknown [8]. We determined the incidence rate of neuroaxial abnormalities in patients with idiopathic scoliosis at our center over 10 years and identified the relationships between intraspinal lesions and age, sex, and curve details.

\section{Materials and Methods}

Neurological examinations and MRI were routinely performed for patients with idiopathic scoliosis requiring surgery. A neurosurgeon was consulted when neuroaxial abnormalities were detected on MRI.

Data related to patients with idiopathic scoliosis at our center between September 2004 and September 2014 were recorded. Patients with congenital, neuromuscular, or syndromic scoliosis and those with incomplete data were excluded. Patients with a neurological deficit and those diagnosed by an orthopedics team (except for asymmetric abdominal cutaneous reflexes), were also excluded. Thus, we enrolled patients with: (1) a spinal deformity as
Table 1. Description of neuroaxial abnormalities detected on preoperative magnetic resonance imaging evaluation

\begin{tabular}{lc} 
Type of neuraxial abnormality & Number 0 case \\
\hline Syrinx with Chiari malformation & 3 \\
\hline Isolated syrinx & 11 \\
\hline Tethered cord & 4 \\
\hline Syrinx with tethered cord & 2 \\
\hline Isolated Arnold Chiari & 2 \\
\hline Hydromyelia & 2 \\
\hline Dural ectasia & 1 \\
Split spinal cord with low lying conus & 2 \\
\hline Total & 27 \\
\hline
\end{tabular}

$\mathrm{MRI}$, magnetic resonance imaging

Table 2. Comparing sex and apex side of deviation

\begin{tabular}{lccc} 
Apex side of & \multicolumn{2}{c}{ Sex } & \\
\cline { 2 - 3 } deviation & Female & Male & \\
Right & 150 & 49 & 199 \\
Left & 58 & 14 & 72 \\
\hline Total & 208 & 63 & 271 \\
\hline
\end{tabular}

the chief complaint, (2) a normal neurological examination (apart from asymmetric abdominal reflexes), (3) no congenital spinal defect on a simple radiograph, and (4) scoliosis requiring medical intervention.

Patients underwent total spinal MRI, and details related to age, sex, age at disease onset, neurological results, presence or absence of neuroaxial abnormalities on MRI, and curve type and size were recorded. These data were compared in patients with and without neuroaxial abnormalities.

\section{Results}

We enrolled 271 (208 females and 63 males) surgical candidates who qualified for inclusion in the study. Twentyseven patients (9.9\%) showed neuroaxial abnormalities on presurgical MRI. The patient characteristics of age, sex, direction and size of the curve, and MRI results were recorded, and the abnormalities and frequencies of each anomaly are shown in Table 1.

Scoliosis curvature was the same in male and female patients $(p=0.362$ ) (Table 2). Table 3 presents the dis- 
Table 3. Comparison between patients with and without neuroaxial anomaly on preoperative magnetic resonance imaging

\begin{tabular}{|c|c|c|c|c|}
\hline Variable & $\begin{array}{l}\text { Patients with no neural } \\
\text { anomaly ( } \mathrm{n}=244)\end{array}$ & $\begin{array}{l}\text { Patients with neural } \\
\text { anomaly }(n=27)\end{array}$ & Statistic analysis & $p$-value \\
\hline Male:female (ratio) & $52: 192(1: 3.6)$ & $11: 16(1: 1.45)$ & Chi-square & 0.024 \\
\hline Degree of curve & $63.2 \pm 19.7$ & $69.5 \pm 19.6$ & Independent $t$-test & 0.217 \\
\hline Right:left (ratio)a) & $177: 67(2.6: 1)$ & $22: 5(4.4: 1)$ & Chi-square & 0.313 \\
\hline Average at presentation (yr) & $14.05 \pm 2.47$ & $12.8 \pm 3.06$ & Independent $t$-test & 0.017 \\
\hline
\end{tabular}

${ }^{a)}$ Side of curve.

Table 4. Neurosurgical procedures in idiopathic scoliosis with neuroaxial abnormalities

\begin{tabular}{llcll} 
No. & \multicolumn{1}{c}{ Diagnosis } & Age $(\mathrm{yr})$ & Sex & \multicolumn{1}{c}{ Neurosurgical procedure } \\
\hline 1 & Syrinx with tethered cord & 14 & Female & Tethered cord release \\
\hline 2 & Tethered cord & 14 & Female & Tethered cord release \\
\hline 3 & Large syrinx & 12 & Male & Syringotomy \\
\hline 4 & Tethered cord & 13 & Female & Tethered cord release \\
\hline 5 & Arnold Chiari & 14 & Male & Posterior fossa decompression \\
\hline 6 & Tethered cord with diplomyelia & 11 & Female & Tethered cord release \\
\hline 7 & Arnold Chiari & 12 & Male & Posterior fossa decompression \\
\hline 8 & Arnold Chiari with syrinx & 14 & Male & Posterior fossa decompression \\
\hline 9 & Tethered cord & 14 & Female & Tethered cord release \\
\hline 10 & Arnold Chiari with syrinx & 6 & Female & Posterior fossa decompression \\
\hline 11 & Arnold Chiari with syrinx & 18 & Male & Posterior fossa decompression with syringotomy \\
\hline 12 & Arnold Chiari with syrinx & 10 & Female & Post fossa decompression \\
\hline 13 & Syrinx with tethered cord & 12 & Male & Tethered cord release \\
\hline 14 & Tethered cord & 14 & Male & Tethered cord release \\
\hline
\end{tabular}

tribution of patients in terms of sex. Eleven of 63 male patients had neuroaxial abnormalities, whereas only 16 of 208 female patients had anomalies $(p=0.024)$. No difference was found between direction (right or left) and size of the curve and neuroaxial abnormalities $(p=0.313$ and $p=0.217$, respectively). However, patients with a neural anomaly were significantly younger $(p=0.017)$.

A neurosurgical procedure was performed preoperatively in 14 of the 27 patients (51\%). Table 4 shows the neurosurgical procedures, and Figs. 1 and 2 show the presurgery MRI and radiographic abnormalities in two patients.

\section{Discussion}

No clear MRI screening guidelines exist for patients with idiopathic scoliosis. Recommended indications for MRI in the literature include pain, rapid progression, left thoracic deformity, neurologic disorder [1], early onset $[9,10]$, double thoracic curvature [11,12], and male sex [13]. Several studies have reported the incidence of intracanal impairments in patients with idiopathic scoliosis, some of which are briefly cited below.

Gupta et al. [14] reported that $18 \%$ to $20 \%$ of 98 patients with idiopathic scoliosis had neuroaxial problems. However, the effects of age, sex, and type of curve were not assessed. Ouellet et al. [15] studied 93 patients but did not report the incidence neuroaxial abnormalities; however, a relationship was reported between neuroaxial abnormalities, male sex, and a left curve, but not with age.

Nakahara et al. [16] reported that $3.8 \%$ of 472 patients had neuroaxial abnormalities, which was directly related to factors, such as early onset $<11$ years of age, male sex, neurological results, and size of the curve. Rajasekaran et 

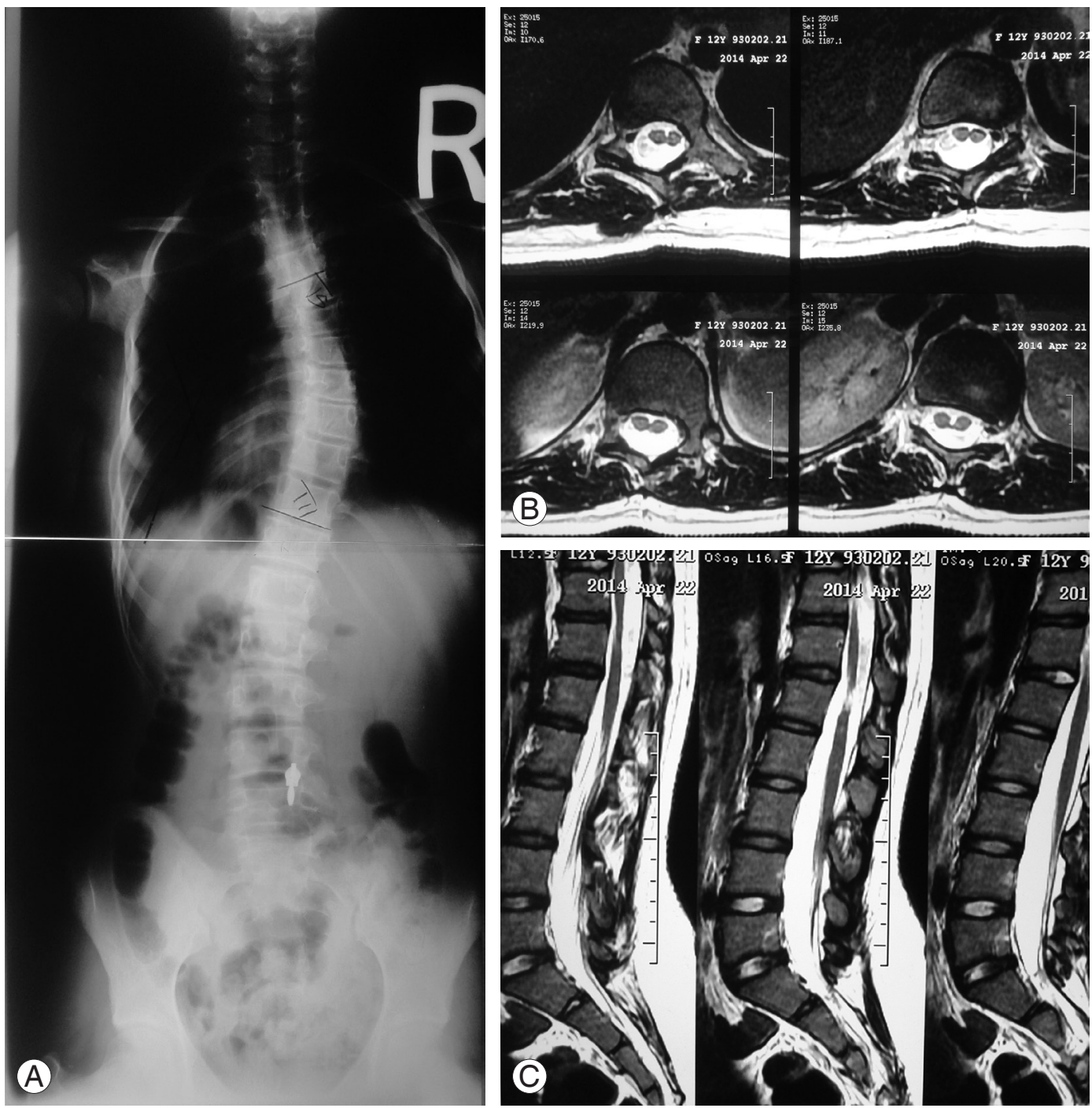

Fig. 1. (A) An 11-year-old female with idiopathic adolescent scoliosis with a right thoracic curve, (B) diplomyelia and (C) low conus at $L 3$ and a tetherd cord on magnetic resonance imaging. She had a normal neurological exam and was operated on for release of a tethered cord before the scoliosis treatment.

al. [17] reported that $16 \%$ of 94 patients had neuroaxial abnormalities and believed that the incidence of neuroaxial lesions was related to a double curve, neurological results, and disease incidence but unrelated to curve size and an atypical curve.

The prevalence of neuroaxial abnormalities in patients with idiopathic scoliosis differs among studies. Patients with specific neurologic abnormalities, such as a positive Babinski reflex or an exaggerated deep tendon reflex, were included in studies reporting a high prevalence, whereas only juveniles or adolescents were included in studies reporting a low prevalence. In the present study, all patients with idiopathic scoliosis, including juveniles and adolescents, were enrolled, but patients with a specific neurological disorder (except for symmetric abdominal reflexes) were excluded.

Male sex is an important factor predicting potential neuroaxial lesions $[15,16]$. Yet, some studies have reported inconsistencies with this result [18-20]. We found a significant relationship between male sex and neuroaxial abnormalities.

A left-sided thoracic curve has been highly associated with neuroaxial abnormalities $[8,21]$, whereas other studies report contrasting results [22]. We found no relationship between a left apex and the incidence of neuroaxial abnormalities. Curve size has been investigated at disease presentation, but most studies found no relationship between curve size and the incidence of neuroaxial ab- 

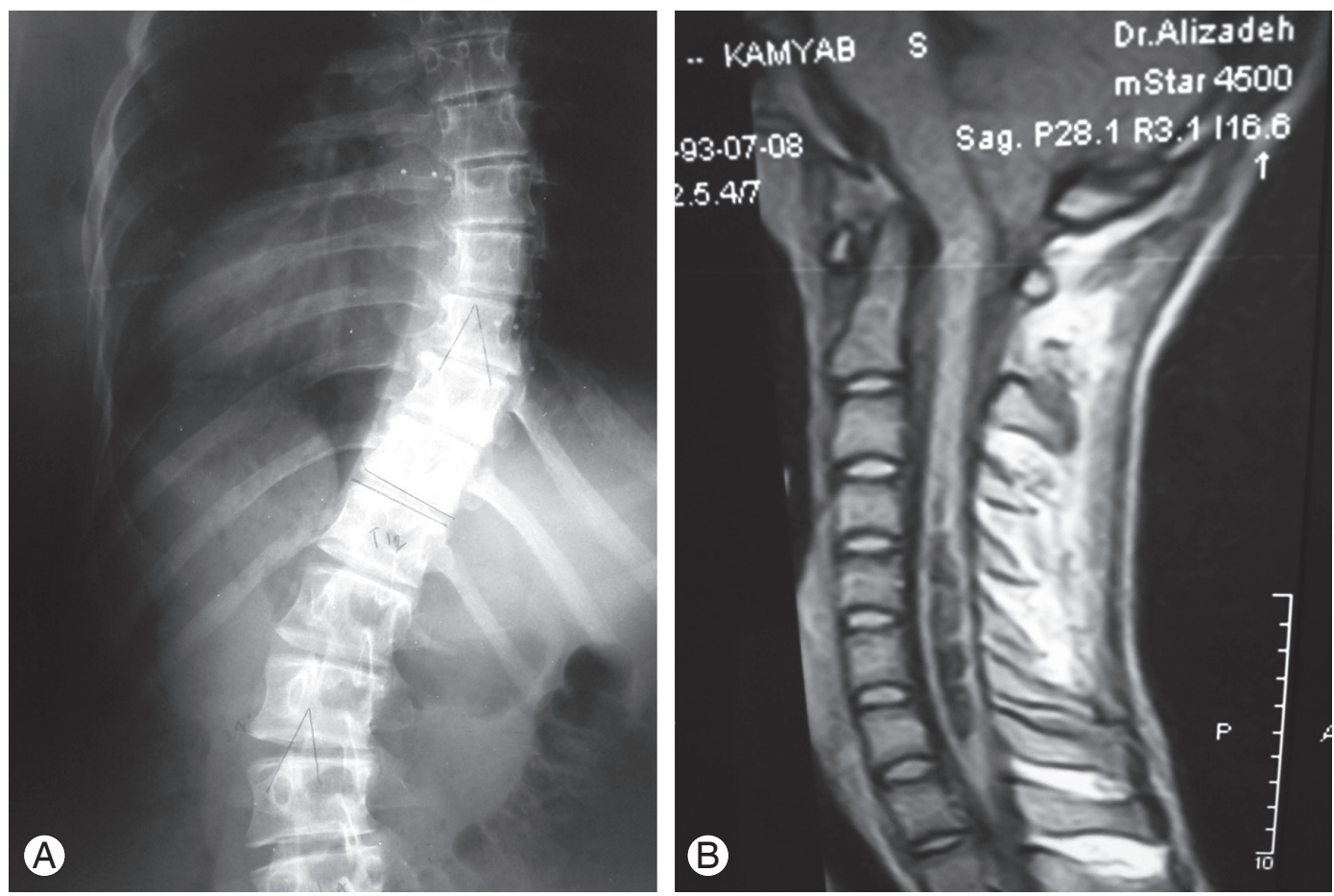

Fig. 2. (A) An 18-year-old male with a right thoracic curve, (B) large syrinx at the cervix, and an Arnold Chiari malformation on a cervical magnetic resonance image that required neurosurgery before correcting the scoliosis.

normalities $[17,19,20,22,23]$. We did not find a relationship between curve size and the incidence of neuroaxial abnormalities.

A patient's age at disease presentation is another factor that has not been related to neuroaxial abnormalities $[15,20,21]$, whereas other studies found a relationship between early disease onset and neuroaxial abnormalities $[16,17,21]$. We found that patients with neuroaxial abnormalities developed scoliosis at a younger age.

\section{Conclusions}

Neuroaxial abnormalities are prevalent in patients with idiopathic scoliosis (9.9\%). Although factors, such as age, curve size, atypical curve, sex, or a normal neurological examination, rule out neuroaxial lesions, performing MRI is essential in all patients with idiopathic scoliosis requiring medical intervention. Furthermore, failure to identify these abnormalities before corrective surgery (distraction force) can result in the development of central nervous system lesions. Identifying and treating these abnormalities may prevent curve progression or improve curvature $[24,25]$. This is particularly true in cases of syrinx and a tethered cord. We found a relationship between neuroaxi- al abnormalities, young age, and male sex. Therefore, neuroaxial abnormalities are more likely in male patients and in patients with early onset idiopathic scoliosis disease.

\section{Conflict of Interest}

No potential conflicts of interest relevant to this article are reported.

\section{Acknowledgments}

This study was carried out at the Bone and Joint Reconstruction Center, Department of Orthopaedic Surgery, Shafa-Yahiaeian Hospital, Iran University of Medical Sciences, Tehran, Iran.

\section{References}

1. Warner WC, Sawyer JR, Kelly DM. Scoliosis and kyphosis. In: Canale ST, Beaty JH, editors. Campbell's operative orthopaedics. 12th ed. Philadelphia: Elsevier-Mosby; 2013. p.1691-895.

2. Singhal R, Perry DC, Prasad S, Davidson NT, Bruce $\mathrm{CE}$. The use of routine preoperative magnetic reso- 
nance imaging in identifying intraspinal anomalies in patients with idiopathic scoliosis: a 10-year review. Eur Spine J 2013;22:355-9.

3. Noordeen MH, Taylor BA, Edgar MA. Syringomyelia. A potential risk factor in scoliosis surgery. Spine (Phila Pa 1976) 1994;19:1406-9.

4. Ozerdemoglu RA, Denis F, Transfeldt EE. Scoliosis associated with syringomyelia: clinical and radiologic correlation. Spine (Phila Pa 1976) 2003;28:1410-7.

5. MacEwen GD, Bunnell WP, Sriram K. Acute neurological complications in the treatment of scoliosis. A report of the Scoliosis Research Society. J Bone Joint Surg Am 1975;57:404-8.

6. Stokes IA. Three-dimensional terminology of spinal deformity. A report presented to the Scoliosis Research Society by the Scoliosis Research Society Working Group on 3-D terminology of spinal deformity Spine (Phila Pa 1976) 1994;19:236-48.

7. Peer S, Krismer M, Judmaier W, Kerber W. The value of MRI in the preoperative assessment of scoliosis. Orthopade 1994;23:318-22.

8. Schwend RM, Hennrikus W, Hall JE, Emans JB. Childhood scoliosis: clinical indications for magnetic resonance imaging. J Bone Joint Surg Am 1995;77:4653.

9. Evans SC, Edgar MA, Hall-Craggs MA, Powell MP, Taylor BA, Noordeen HH. MRI of 'idiopathic' juvenile scoliosis. A prospective study. J Bone Joint Surg Br 1996;78:314-7.

10. Lewonowski K, King JD, Nelson MD. Routine use of magnetic resonance imaging in idiopathic scoliosis patients less than eleven years of age. Spine (Phila $\mathrm{Pa}$ 1976) 1992;17(6 Suppl):S109-16.

11. Bertrand SL, Drvaric DM, Roberts JM. Scoliosis in syringomyelia. Orthopedics 1989;12:335-7.

12. Maiocco B, Deeney VF, Coulon R, Parks PF Jr. Adolescent idiopathic scoliosis and the presence of spinal cord abnormalities. Preoperative magnetic resonance imaging analysis. Spine (Phila Pa 1976) 1997;22: 2537-41.

13. Tokunaga M, Minami S, Isobe K, Moriya H, Kitahara H, Nakata Y. Study on the scoliosis complicated with syringomyelia. Spinal Deformity 1997;22:855-88.

14. Gupta P, Lenke LG, Bridwell KH. Incidence of neural axis abnormalities in infantile and juvenile patients with spinal deformity. Is a magnetic resonance image screening necessary? Spine (Phila Pa 1976) 1998;23: 206-10.

15. Ouellet JA, LaPlaza J, Erickson MA, Birch JG, Burke S, Browne R. Sagittal plane deformity in the thoracic spine: a clue to the presence of syringomyelia as a cause of scoliosis. Spine (Phila Pa 1976) 2003;28: 2147-51.

16. Nakahara D, Yonezawa I, Kobanawa K, et al. Magnetic resonance imaging evaluation of patients with idiopathic scoliosis: a prospective study of four hundred seventy-two outpatients. Spine (Phila Pa 1976) 2011;36:E482-5.

17. Rajasekaran S, Kamath V, Kiran R, Shetty AP. Intraspinal anomalies in scoliosis: an MRI analysis of 177 consecutive scoliosis patients. Indian J Orthop 2010; 44:57-63.

18. Inoue M, Minami S, Nakata $Y$, et al. Preoperative MRI analysis of patients with idiopathic scoliosis: a prospective study. Spine (Phila Pa 1976) 2005;30:10814.

19. Dobbs MB, Lenke LG, Szymanski DA, et al. Prevalence of neural axis abnormalities in patients with infantile idiopathic scoliosis. J Bone Joint Surg Am 2002;84:2230-4.

20. Davids JR, Chamberlin E, Blackhurst DW. Indications for magnetic resonance imaging in presumed adolescent idiopathic scoliosis. J Bone Joint Surg Am 2004;86:2187-95.

21. Geissele AE, Kransdorf MJ, Geyer CA, Jelinek JS, Van Dam BE. Magnetic resonance imaging of the brain stem in adolescent idiopathic scoliosis. Spine (Phila Pa 1976) 1991;16:761-3.

22. Lee RS, Reed DW, Saifuddin A. The correlation between coronal balance and neuroaxial abnormalities detected on MRI in adolescent idiopathic scoliosis. Eur Spine J 2012;21:1106-10.

23. Pahys JM, Samdani AF, Betz RR. Intraspinal anomalies in infantile idiopathic scoliosis: prevalence and role of magnetic resonance imaging. Spine (Phila Pa 1976) 2009;34:E434-8.

24. Yeom JS, Lee CK, Park KW, et al. Scoliosis associated with syringomyelia: analysis of MRI and curve progression. Eur Spine J 2007;16:1629-35.

25. Sawyer JR. Paralytic disorders. In: Canale ST, Beaty $\mathrm{JH}$, editors. Campbell's operative orthopaedics. 12th ed. Philadelphia: Elsevier-Mosby; 2013. p.1255-335. 